\title{
Stress among Female Medical Students in selected Medical Colleges of Dhaka City in Bangladesh
}

\author{
N Farzana ${ }^{1}$, M Shahjahan ${ }^{2}$, S K Nayan ${ }^{3}$
}

\begin{abstract}
Background : Stress is body's way of responding to any kind of change that requires a physical, mental or emotional adjustment. Medical students are subjected to stress by strenuous medical programs, which may have physical and psychological effects on their well-being.

Objectives : To determine level of stress among 3rd and 4th year female medical students in selected medical colleges of Dhaka city.

Materials and methods: Descriptive, cross sectional study was carried out on the female students of 3rd year and 4th year of Sir Salimullah Medical College and Northern International Medical College located in Dhaka city during JanuaryMarch 2016. The medical colleges were selected using purposive sampling technique. Sample size was 296 female students and data were collected by self administered semi structured pretested questionnaire. PMSS scale (Perceived Medical School Stress Scale) was used to find out the level of stress among the respondents.
\end{abstract}

Results : From the current study it was found that about $82 \%$ female medical students had moderate level of stress according to PMSS (Perceived Medical School Stress Scale), 6\% and 12\% had high level and low level of stress respectively. Statistically significant association was found between level of stress and medical college curriculum $(p=0.000)$,academic environment $(p=0.000)$, social and recreational life $(p=0.000)$, worries about study and performance $(p=0.004)$, worries about finance $p=0.005)$, worries about accommodation $(p=0.000)$.

Conclusion : In this study, stress in different levels were found among all of the female medical students. About $82 \%$ female medical students had moderate level of stress according to PMSS (Perceived Medical School Stress Scale). The study also revealed that a statistically significant association between level of stress and medical college curriculum, academic environment ,social and recreational life, worries about study and performance, worries about finance and accommodation.

Key Words : Stress, PMSS scale.

Northern International Medical College Journal Vol. 8 No. 01 July 2016, Page 181-184

${ }^{2}$ Major General (Retd.) Dr. M Shahjahan MBBS, MCPS(BD), MD(Pune)

Professor of Public Health

Management and Administration

Dept. of Public Health

State University of Bangladesh

3 Dr. Safia Khatun Nayan

MBBS, MPH

Asst. Professor

Dept. of Community Medicine

Northern International Medical

College, Dhaka

Correspondence

Dr. Nashid Farzana

MBBS,MPH

Lecturer

Dept. of Community Medicine

Northern International Medical

College, Dhaka

E mail: nashidf@gmail.com

\section{Introduction}

Stress is the "wear and tear" our bodies experience as we adjust to our continually changing environment; it has physical and emotional effects and can create positive or negative influence on us. ${ }^{1}$ Throughout the world all health professionals face stress because of time-pressures, workload, multiple roles and emotional issues. Stress does not only exist among the health professionals but also in medical students. Medical education is generally perceived as being stressful. High rates of psychological morbidity among students, such as anxiety and depressive symptoms, have been reported in several studies. ${ }^{2}$ Stress experienced by medical students start from the beginning of the training process. ${ }^{3}$ Although some degree of stress is accepted as a normal part of medical training and can be a motivator for some individuals, not all students find the stress manageable.

Bangladesh has currently 104 medical colleges 30 of which are public, 68 are private and 6 are armed force medical college. The gender ratio among medical students indicates $68 \%$ female to $32 \%$ male and this ratio is increasing day by day. ${ }^{4}$ During $3^{\text {rd }}$ and $4^{\text {th }}$ year medical students pass middle stage of medical study as they have already overcome the initial hesitance of entering and adjusting medical study and adopted some coping capability to finish the study in time. Besides this many studies have been conducted in developed world to evaluate the stress level among medical students but not much in the 
developing countries. A study conducted in Bangladesh shows $54 \%$ medical students suffering from stress. ${ }^{1}$ Although these studies showed overall picture of mental status of both male and female medical students, very few have specified about the female group which is more than half of the entire medical students group.

Therefore considering all these issues we had selected $3^{\text {rd }}$ and $4^{\text {th }}$ year medical students of both private and public medical colleges to determine the prevalence of stress, perceived level of stress, common stress related factors among the female medical students of Dhaka city in Bangladesh.

\section{Materials and Methods}

This descriptive cross sectional study was done during January to March 2016 in two medical colleges of Dhaka city. All female students of $3^{\text {rd }}$ year and $4^{\text {th }}$ year of Sir Salimullah Medical College and Northern International Medical College were chosen purposively. Prevalence used for this study was $55 \%$ or 0.55 according to the reference study ${ }^{2}$ to determine the sample size for current study. The desired sample size was 380 but due to constraint of time and resources the sample size was taller 296 and self administered semi structured pretested questionnaire was used as data collection tool of the study. From Likert scale, PMSS scale (Perceived Medical School Stress Scale) was used to find out the level of stress among the respondents.

\section{PMSS scale (Perceived Medical School Stress Scale):}

Each of the 13 items related to factors given below has a fivepoint Likert scale, ranging from "strongly disagree $=0$ " to "strongly agree $=4 "$ ". The total score of the items is used to indicate the level of stress among the students, where a high score indicated a high level of perceived stress. In this study factors of this scale were:

- Medical school curriculum - from the statement 'I am concerned that I will unable to master the entire pool of medical knowledge'

- Academic environment- from the statement 'Medical school is cold, impersonal and needlessly bureaucratic (Bureaucracies have been criticized as being too complex, inefficient, or too inflexible.)'

- Social / recreational life - from the statement' Medical training controls my life and leaves too little time for other activities like social work or recreation.'

- Worries about study and performance -from the statement 'I am concerned that I will not be able to endure the long hours and responsibilities associated with clinical training and practice.'

- Worries about finance-from the statement 'Personal finances are a source of concern to me'

- Worries about accommodation- from the statement 'Accommodation is a source of concern to me'

\section{Interpretation}

$0-20=$ Low level of stress/21-35=Moderate level of stress $/ 36-52=$ High level of stress

The respondents were provided with 4 questions to assess the perceived knowledge regarding stress. The questions were about meaning of stress, effects of stress on body, effect of stress on behavior and common measures of reducing stress.

All of them 3 were multiple choice questions and 1 was single answered question.

Data analysis were done with the help of SPSS 16 and MS excel. Pertinent results were tabulated.

\section{Results}

Among the respondents of the current study, $61 \%$ female students studying in $3^{\text {rd }}$ and $4^{\text {th }}$ years were in the age group of 21-22 years. Minimum age was 20 years and maximum age was 28 years. Most of the students $96 \%$ were unmarried. More than half of the respondents' $60 \%$ monthly family income was around 50000 taka (table-I).

Table I : Distribution of Socio demographic factors of respondents $(n=296)$

Socio demographic factors

Age Group

20-22 years

23-25 years

$>25$ years

\section{Marital status}

Married

Unmarried

\section{Monthly income of family}

50000 taka

51000 to 150000 taka

151000 to 300000 taka

$>300000$ taka

In this study 204 (69\%) sample were taken from public medical college and $92(31 \%)$ were from private medical college. (Figure 1)

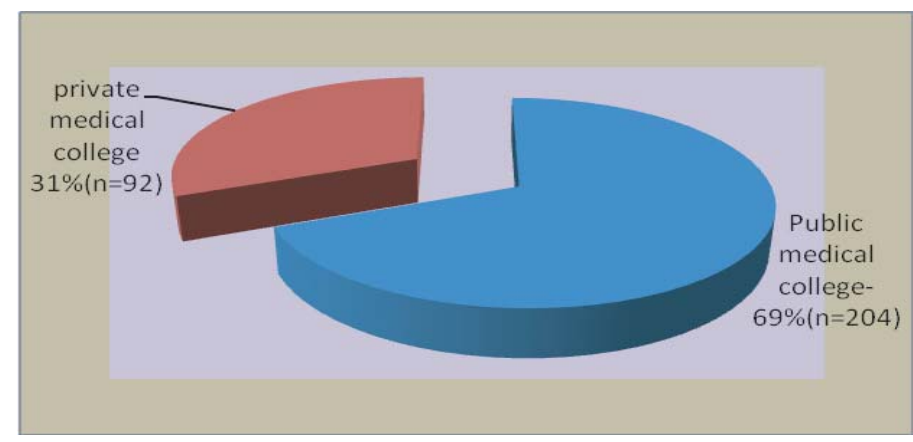

Figure 1 : Distribution of respondents by type of medical college 
On asking about meaning of stress about $97 \%$ of the students answered correctly (Figure 2).

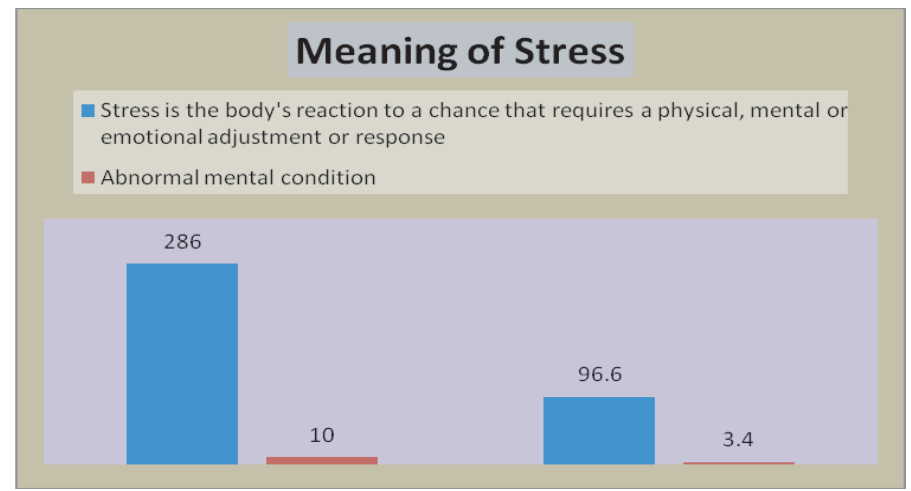

Figure 2 : Distribution of respondents by the perceived knowledge on meaning of stress: $(n=296)$

Regarding the effects of stress on body highest frequency of the students mentioned Headache $82 \%$. Other answered Tendency to sweat $63.85 \%$, Back and chest pain $61.14 \%$, Obesity $53 \%$, Heart disease $70.27 \%$, Hypertension $68.58 \%$, Stomach upset $59.79 \%$ as effects of stress on body.

In answering the question about effects of stress on behavior $62.5 \%$ answered Social withdrawal other responses were food craving $50.67 \%$, Eating too little $62.5 \%$, Relationship problem $57.77 \%$, Higher tobacco consumption 52\%, drug abuse 53\%.

In response to the question regarding common measures of reducing stress highest frequency of the students mentioned Sharing problem with family and friends $65.54 \%$ and taking rest $67.56 \%$ Other answered Watching TV and movie $60.80 \%$, Self counseling $55.40 \%$, prayers $67.22 \%$, Meditation and yoga $53.04 \%$, Eating 54\%, games $45.60 \%$, Smoking and taking other sedatives $57.77 \%$, self harm (Physical ) 42.56\% (table II).

Table II: Distribution of respondents by perceived knowledge about effects of stress on body, effect on behavior, common measures of reducing stress $(n=296)$

$\begin{array}{lcc}\text { Effects of stress on body } & \text { Frequency } & \text { Percent } \\ \text { Tendency to sweat } & 189 & 63.85 \% \\ \text { Back and chest pain } & 181 & 61.14 \% \\ \text { Obesity } & 157 & 53.04 \% \\ \text { Headache } & 243 & 82.09 \% \\ \text { Heart disease } & 208 & 70.27 \% \\ \text { Hypertension } & 203 & 68.58 \% \\ \text { Stomach upset } & 177 & 59.79 \% \\ \text { Effect on behavior } & \text { Frequency } & \text { Percent } \\ \text { Food craving } & 150 & 50.67 \% \\ \text { Eating too little } & 185 & 62.5 \% \\ \text { Social withdrawal } & 185 & 62.5 \% \\ \text { Relationship problem } & 171 & 57.77 \% \\ \text { Higher tobacco consumption } & 154 & 52.02 \% \\ \text { drug abuse } & 157 & 53.04 \% \\ \text { Common measures of reducing stress } & & \\ \text { Sharing problem with family and friends } & 194 & 65.54 \% \\ \text { Watch TV and movie } & 180 & 60.81 \% \\ \text { Self counseling } & 164 & 55.40 \% \\ \text { prayers } & 199 & 67.22 \% \\ \text { Meditation and yoga } & 157 & 53.04 \% \\ \text { Taking rest } & 200 & 67.56 \% \\ \text { Eating } & 160 & 54.05 \% \\ \text { games } & 135 & 45.60 \% \\ \text { Smoking and taking other sedatives } & 171 & 57.77 \% \\ \text { self harm (Physical) } & 126 & 42.56 \%\end{array}$

*Multiple Response

In order to assess the level of stress PMSS scale was used. Following table shows the distribution of the responses of the female medical students according to PMSS Scale.

According to PMSS scale $82.1 \%(n=243)$ female students had moderate level of stress, $5.7 \%(n=17)$ students had high stress,

Table III : Level of Stress according to PMSS scale Interpretation and distribution of the responses of the female medical students $(n=296) .0$ to $20=$ low level of stress, 21-35 = moderate level of stress, 36-52 = high level of stress.

\begin{tabular}{|c|c|c|c|c|c|c|}
\hline & Statements & \begin{tabular}{c|c} 
Strongly \\
disagree=0
\end{tabular} & $\begin{array}{l}\text { Disagree } \\
\quad=1\end{array}$ & $\begin{array}{l}\text { Neutral } \\
=2\end{array}$ & $\begin{array}{l}\text { Agree } \\
=3\end{array}$ & $\begin{array}{l}\text { Strongly } \\
\text { Agree }=4\end{array}$ \\
\hline 1 & Medical school fosters a sense of anonymity and feelings of isolation among the students. & $12.8 \%$ & $23.3 \%$ & $32.8 \%$ & $26.0 \%$ & $5.1 \%$ \\
\hline 2 & $\begin{array}{l}\text { I am concerned that I will not be able to endure the long hours and responsibilities } \\
\text { associated with clinical training and practice }\end{array}$ & $32.7 \%$ & $26.9 \%$ & $26.5 \%$ & $2.5 \%$ & $11.4 \%$ \\
\hline 3 & I do not know what the faculty/administration expect of me & $33.9 \%$ & $3.2 \%$ & $34.9 \%$ & $23.1 \%$ & $4.9 \%$ \\
\hline 4 & $\begin{array}{l}\text { Medical training controls my life and leaves too little time for other activities like social } \\
\text { work or recreation. }\end{array}$ & $3.7 \%$ & $13.5 \%$ & $29.4 \%$ & $31.8 \%$ & $21.6 \%$ \\
\hline 5 & I am concerned that I will unable to master the entire pool of medical knowledge & $.7 \%$ & $29.1 \%$ & $27.7 \%$ & $39.8 \%$ & $2.7 \%$ \\
\hline 6 & $\begin{array}{l}\text { This medical school is fostering a physician role at the expense of one's personality and } \\
\text { interests }\end{array}$ & $26.4 \%$ & $29.6 \%$ & $32.6 \%$ & $2.9 \%$ & $8.5 \%$ \\
\hline 7 & Medical school is more competitive than I expected & $4.1 \%$ & $32.5 \%$ & $40.5 \%$ & $12.0 \%$ & $10.9 \%$ \\
\hline 8 & $\begin{array}{l}\text { The attitude of too many of the faculty is that students should be subjected to 'baptism of } \\
\text { fire'.(baptism of fire: a difficult introduction to a new job or activity) }\end{array}$ & $14.5 \%$ & $45.8 \%$ & $22.8 \%$ & $6.8 \%$ & $10.1 \%$ \\
\hline 9 & $\begin{array}{l}\text { The majority of students feel that success in medical school is in spite of the } \\
\text { administration rather than because of it }\end{array}$ & $6.1 \%$ & $45.6 \%$ & $36.8 \%$ & $2.8 \%$ & $8.7 \%$ \\
\hline 10 & Medical school is cold, impersonal and needlessly bureaucratic & $16.8 \%$ & $33.5 \%$ & $24.8 \%$ & $14.1 \%$ & $0.8 \%$ \\
\hline 11 & Medical school is more of a threat than a challenge & $36.5 \%$ & $23.6 \%$ & $14.5 \%$ & $10.6 \%$ & $14.8 \%$ \\
\hline 12 & Personal finances are a source of concern to me & $22.4 \%$ & $31.4 \%$ & $14.5 \%$ & $10.1 \%$ & $21.6 \%$ \\
\hline 13 & Accommodation is a source of concern to me & $26.7 \%$ & $24.3 \%$ & $9.5 \%$ & $16.9 \%$ & $22.6 \%$ \\
\hline
\end{tabular}


$12.2 \%(n=36)$ students had low level of stress (Figure 3).

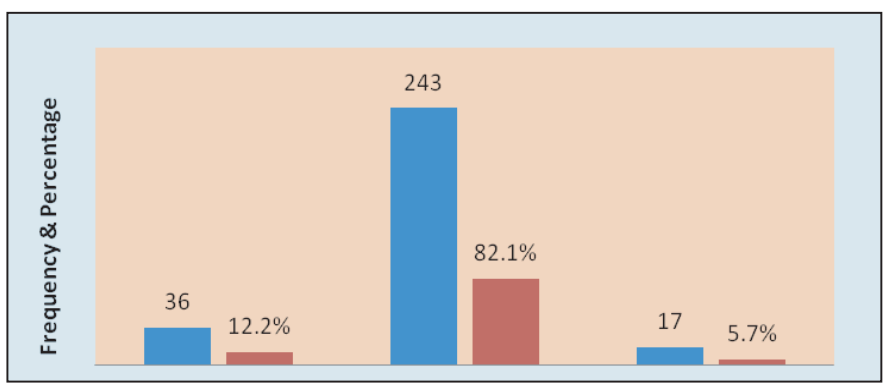

Figure 3 : Distribution of students according to level of stress: $(n=296)$

Statistically significant association was found between level of stress and medical college curriculum, academic environment social and recreational life, worries about study and performance, worries about finance, worries about accommodation (table IV)

Table IV : Association of different factors and level of stress among the female medical students $(n=296)$

\section{Factors}

Medical College curriculum Academic environment Social/recreational life

Worries about study

Personal finance

Accommodation problem

*Multiple Response

\begin{tabular}{cclc} 
Low & $\begin{array}{c}\text { Stress Level } \\
\text { Moderate }\end{array}$ & High & P value \\
$5.6 \%$ & $32.1 \%$ & $69.6 \%$ & 0.000 \\
$19.5 \%$ & $64.6 \%$ & $64.60 \%$ & 0.000 \\
$27.80 \%$ & $53.90 \%$ & $100.00 \%$ & 0.000 \\
$0.00 \%$ & $3.30 \%$ & $11.80 \%$ & 0.004 \\
$22.30 \%$ & $31.30 \%$ & $58.80 \%$ & 0.005 \\
$19.40 \%$ & $39.90 \%$ & $76.50 \%$ & 0.000 \\
\multicolumn{4}{c}{$*$ significant $p=<0.05$}
\end{tabular}

The study did not found any significant association between age of medical student and level of stress $(P=0.671)$, between monthly income of family $(\mathrm{P}=0.750)$ and level of stress.

\section{Discussion}

This study concerned only about female medical students and found that $82 \%$ had moderate level of stress according to PMSS (Perceived Medical School Stress Scale), $6 \%$ had high level of stress .On the other hand a cross-sectional study was conducted at a College of Medicine in Saudi Arabia in 2011 observed that the total prevalence of stress was $63 \%$, and the prevalence of severe stress was $25 \%$. The prevalence of stress was higher $(p<0.5)$ among females $(75.7 \%)$ than among males $(57 \%) .^{5}$ Another study was conducted at Dhaka Medical College during the period of April 2009 found that over one third (34.6\%) had mild stress, (39.8\%) moderate stress and about one fourth (24.9\%) was suffering from severe stress according to Kessler 10 Psychological distress scale. ${ }^{6} \mathrm{~A}$ study 'Stress among medical students in a Thai medical school.' showed that about $61.4 \%$ of students had some degree of stress. The prevalence of stress is highest among third-year medical students. ${ }^{7}$ Academic problems were found to be a major cause of stress among all students. The current study was done focusing only the female medical students of $3^{\text {rd }}$ and $4^{\text {th }}$ year and observed significant association between level of stress and stress related factors. Hamza M. Abdulghani et al conducted a study ' Stress and Its Effects on Medical Students: A Cross-sectional Study at a College of Medicine in Saudi Arabia" observed association between stress and being female $(p<0.0001)$, year of study $(p<0.001)$, and presence of perceived physical problems $(p<0.0001) .{ }^{5}$ whereas the current study found statistically significant association between level of stress and medical college curriculum $(p=0.000)$, academic environment $(p=0.000)$ and recreational life $(p=0.000)$. Study conducted in India in January 2014, found that more than half of the respondents were affected by depression (51.3\%), anxiety $(66.9 \%)$ and stress (53\%). Morbidity was found to be more in 5th semester students rather than students of 2nd semester. Females reported higher score as compared to their male counterparts. ${ }^{8}$ This study was conducted focusing $3^{\text {rd }}$ and $4^{\text {th }}$ years female medical students and found that $82 \%$ were moderately stressed. In the current study $54 \%$ students who agreed with the statement 'Medical training controls my life and leaves too little time for other activities like social work or recreation.' Have moderate level of stress. $(P=0.000)$.

The coping strategies of Bangladeshi medical students were different from those reported by other studies. ${ }^{5-7}$ The different coping mechanism for stress reported by the students' includes sharing any problem with family and friends (65.54\%) watching television and movies (60.81\%) etc. Academic-stress was reported to be the most stressful by Bangladeshi medical students. Therefore, relevant authorities need to address this issue in order to produce high-quality professional and holistic medical doctors for the country.

\section{Conclusion}

In this study, stress in different levels were found among all of the female medical students. About $82 \%$ female medical students had moderate level of stress according to PMSS (Perceived Medical School Stress Scale). The study also revealed that a statistically significant association between level of stress and medical college curriculum, academic environment, social and recreational life, worries about study and performance, worries about finance and accommodation.

\section{References}

1. Behere SP, Yadav R, Behere PB .A comparative study of stress among students of medicine, engineering, and nursing. Indian J Psychol Med 2011; 33(2):145-148.

2. Dyrbye LM, Thomas MR, Shana felt TD Medical student stress: causes, consequences, and proposed solutions. Mayo Clin Proc 2005 80(12):1613-1622.

3. List of medical colleges in Bangladesh https://en.wikipedia.org/wiki/ List_of_medical_colleges_in_Bangladesh.

4. Jain A, Bansal R Stress among medical and dental students: a global issue. IOSR J Dent Med Sci (JDMS) (2012); 1(5):5-7.

5. Hamza M. Abdulghani, Abdulaziz A. AlKanhal, Ebrahim S. Mahmoud, Gominda G. Ponnamperuma, and Eiad A. Alfaris. Stress and Its Effects on Medical Students: A Cross-sectional Study at a College of Medicine in Saudi Arabia. J Health PopulNutr. 2011 Oct; 29(5): 516-522.

6. Sajid A1, Ahmad T2, Khalid T3. Stress in medical undergraduates; its association with academic performance. Bangladesh Journal of Medical Science 2011 March. Vol. 14 No. 02.

7. Saipanish R. Stress among medical students in a Thai medical school. Med Educ. Jun 2005; 39(6):594-604. http://www.ncbi.nlm.nih.gov/ pubmed/ 14522672. September 2003.

8. Shawaz Iqbal, Sandhya Gupta \& E. Venkatarao. stress, anxiety \& depression among medical undergraduate students \& their socio-demographic correlates. Departments of Physiology \& Community Medicine, Institute of Medical Sciences \& SUM Hospital, S 'O'A University, Bhubaneswar, India. Student IJMR. 